Background The last decade has seen dramatic changes in the training needs and number of junior doctors in NNUs in the UK alongside the restriction of working hours - European Working Time Directive (EWTD). Consequently RCHT has introduced ANNPs working on the junior medical rota.

Methods 2 ANNPs replaced the two year 2 Foundation doctors (F2) releasing them for general paediatric experience. 2 further ANNPs then replaced the General Practitioner (GP) trainees. Tier 1 rota is now provided by a combination of three 1 st or 2nd year paediatric speciality trainees (ST) along side the 4 ANNPs.

Results Junior doctors now comply with EWTD. The Royal College of General Practitioner (RCGP) guidance that GP trainees should not be working in NNUs is facilitated.

ANNPs have bridged the gap between the neonatal nurses and the medical staff with education, governance, and management roles.

ANNPs lead bedside education sessions for the medical students alongside developing a medical quiz and 'Newborn Examination' booklet that has been adapted by other medical schools. The ANNPs provide a unique 'buddy' system for ST trainees starting on the neonatal unit. They lead on the neonatal Simulation scenarios, and take part in the regional 'Step up to Registrar' neonatal simulation workshops.

The lead ANNP has been awarded the RCHT 2013 'Excellence and Innovation' award.

Conclusion The advanced skills, knowledge and practice of the ANNPs has improved the quality of service provision along side enhancing the teaching and training of medical students and paediatric ST trainees.

\section{PO-0903 THE PROBLEM OF CONFLICTING OR INSIGNIFICANT RESULTS OF PROMISING NURSING INTERVENTIONS}

J Weis. Neonatology, Copenhagen University Hospital Rigshospitalet, Copenhagen, Denmark

\subsection{6/archdischild-2014-307384.1526}

Background and aim Conflicting or insignificant results of studies into the effect of promising nursing interventions are not uncommon. Recently, we conducted a study into the effect on NICU-related parental stress of a new nurse-parent communication intervention. Surprisingly, we were not able to show the effect of the intervention in a randomised controlled trial although we found that parents experienced the intervention as supportive compared to standard care. The aim of this presentation is to present the conflicting evidence of the effect and significance of the Guided Family-Centred Care (GFCC); discuss possible reasons why we may have been unable to show effect; and discuss potential ways for handling such matters.

Methods Evaluation of the results of the GFCC study within the framework of current literature on challenges of evaluating complex interventions.

Results Lack of effect may not necessarily reflect ineffectiveness of an intervention. In our study, there may be a number of possible explanations for being unable to show effect, such as spill over between the groups, or a too modest "dose" of the intervention. Another explanation might be that the outcome measures were not sensitive to the intervention effect. Results from the interview study indicated that other outcome measures such as parent strength and empowerment might have been relevant. However, such instruments are lacking.
Conclusion It may be necessary to develop new instruments sensitive to human interaction to demonstrate effect of nursing interventions. Furthermore, incorporating multiple methods, sources and perspectives are needed when evaluating effect of complex interventions.

\section{PO-0904 DESCRIBING THE KNOWLEDGE OF PARENTS ABOUT NEWBORN SCREENING}

D Yildiz, B Fidanci, D Konukbay, N Akbayrak. School of Nursing Pediatric Nursing Department, Gulhane Military Medical Academy, Ankara, Turkey

\subsection{6/archdischild-2014-307384.1527}

Screeningis generally consider part of the routine care for newborns. Newborn screening for phenylketonuria (PKU) has been available since the early 1960s. The fist newborn screening for PKU started in Ankara in Turkey in 1986 and extended country wide in 1993. PKU rate in Turkey occurs 1 in 4000 newborns because of consanguineous marriage. Consanguineous marriage rat in Turkey is $21 \%$.

This research was planned to describe the knowledge of parents about newborn PKU screening. A questionnaire was used to gather the data. To determine the effects data were evaulated by using chi square test and percentage analysis on the SPSS 11.0 program package.

The study was performed during the period of January 2005 and March 2005 in a University Hospital and 150 mothers in postpartum period were included in the research. The questionnaire was obtained by face to face technique.

Results The mean age of mothers was $26.49 \%$ of mother were graduated basic school. $74.7 \%$ of mother were house wife. $68 \%$ of mothers were primipara. $47 \%$ of mothers statedthat the test was 'a IQ test'. Sixty-four percent of mothers didn't know how toexecute the test. $69.3 \%$ of mothers didn't know how long to continue the test. $61.3 \%$ of mothers didn't know how to learn the results of the test.

Although99.3\% of newborns were seem to be physically healthy, it was stated thatpostpartum screening tests should be applied. Considering this results, inorder to inform the mothers about the obtained results, a PKU educationbrochure was prepared and given to the unit.

Conclusions Nurses who understand the pathophysiology and management of PKU in pregnancycan provide the care necessary for maternal and neonatal health. Healthcare providersare responsible for informing parents about the implications of newbornscreening to improve awareness and understanding.

\section{P0-0905 WITHDRAWN}

\section{Paediatric Surgery}

\section{PO-0906 INTRAPERITONEAL RUPTURE OF HEPATIC HYDATID CYST FOLLOWING BLUNT ABDOMINAL TRAUMA IN A 7-YEAR-OLD BOY}

C Atabek, MB Caliskan, A Guven, S Demirbag, I Surer. Pediatric Surgery, Gulhane Military Medical Academy, Ankara, Turkey

10.1136/archdischild-2014-307384.1528 